\title{
Effects of Mungbean Flour Level in Combination with Microbial Transglutaminase on Physicochemical and Textural Properties of Low-salt Pork Model Sausages
}

\author{
Hong Chul Lee and Koo Bok Chin* \\ Department of Animal Science, Functional Food Research Center, Chonnam National University, Gwangju 500-757, Korea
}

\begin{abstract}
This study was performed to evaluate the effects of various levels of mungbean flour (MF) (0-2.4\%) on the quality characteristics of pork model sausages (PMS) in experiment 1 and also select the optimum level of MF to enhance the water retention and gelling properties of low-salt PMS (LSPMS) with or without microbial transglutaminase (MTGase) in experiment 2. In experiment 1 , the addition of MF did not affect $\mathrm{pH}$, chemical compositions (fat and moisture contents), color values, and functional properties (expressible moisture, EM (\%) and cooking yield, CY (\%)) of PMS. However, the addition of MF increased the chewiness of PMS and hardness if the mungbean flour at the level of more than $1.2 \%$ was incorporated. Since the interaction between the microbial transglutaminase (MTGase) treatment and MF level was not significant ( $p>0.05$ ), data were pooled by different factors (MTGase treatment and MF level) in experiment 2. MF improved the water binding ability and textural springiness of LSPMS. On the other hand, MTGase treatment decreased the $\mathrm{pH}$ and cooking yield (\%) of LSPMS, but increased most textural properties. In conclusion, the addition of MF could enhance the water retention and textural properties of PMS and LSPMS, regardless of MTGase, when it was added to over 1.2\%. Based on these results, mungbean protein may interact with MTGase on the low-salt comminuted meat systems. Therefore, further study might be needed to understand the mechanisms of interaction between MTGase and functional components induced from MF.
\end{abstract}

Key words: low-salt pork sausages, microbial transglutaminase, mungbean flour, physicochemical and textural properties

\section{Introduction}

Since the demands for the 'Well-being' and 'Lifestyles of Health and Sustainability, LOHAS' increased, lots of researches have been focused on the reformulation of several ingredients such as fat, saturated fatty acids, salt, nitrite, that can cause health problems (Jimenez-Colmenero et al., 2001). The World Health Organization (WHO) and Scientific Advisory Committee on Nutrition also recommended that intake of excessive fat and salt should reduce to prevent metabolic diseases (AHA 2000; SACN, 2003). Thus, reduced levels of fat and salt are required to process meat and meat products with health (JimenezColmenero et al., 2001). Research results are necessary to show meat and meat products containing functional ingredients to compensate for the fat and salt (Arihara, 2006; Fernandez-Gines et al., 2005).

\footnotetext{
*Corresponding author: Koo Bok Chin, Department of Animal Science, Chonnam National University, Gwangju 500-757, Korea. Tel: 82-62-530-2121, Fax: 82-62-530-2129, E-mail: kbchin@ jnu.ac.kr
}

Since reducing salt in meat processing leads to the decreases of salt soluble protein extraction, low-salt meat products cause reduced yield and textural problems (Trout and Schmidt, 1984). To solve these problems, various functional ingredients in the manufacture of emulsified-meat products were applied to improve the yields and textural characteristics. Chin and Lee (2002) reported that functional ingredients, such as non-meat proteins and non-starch polysaccharides, are required to develop the low-fat/salt meat products. Among non-meat proteins, soy protein isolate (SPI) has been extensively used in processed meat industry (Rakosky, 1970), because it improved functional and textural properties of low-fat/salt meat products when it was combined with other functional ingredients (Min and Green, 2008).

Microbial transglutaminase (MTGase) has been widely used for food industry to improve the textural characteristics. Especially, MTGase can make a gel without heating process, and heat-induced gels were not melted even at an increased temperature (Motoki and Seguro, 1998). These characteristics were partially due to the formation of cross-linkages ( $\varepsilon$ - $(\gamma$-glutamyl)lysyl) by catalyzing between 
glutamine and lysine (Kashiwagi et al., 2002). Motoki and Seguro (1998) described that MTGase treatments can form the gels as combined with food proteins. It also induced to form emulsion gel in combination with sugar or salt, resulting in improved gel strength after heating. For these characteristics, MTGase was used to modify the functional properties of various kinds of food products (Kuraishi et al., 2001). Recently, application of MTGase has also concerned in plant proteins (Dube et al., 2007).

Legumes have been extensively used as economical food protein resources in the undeveloped countries. Nutritional values and functions of legume seed proteins (LSP) were reported by several previous reports (Duranti and Gius, 1997; Martins and Netto, 2006). Especially, LSP was suggested as a health beneficial compound to reduce risk of coronary heart diseases and cancers (AHA, 2006; Larkin et al., 2008). Recently, Korean researchers identified legume seeds to prevent the stomach cancer (Ko et al., 2010).

Mungbean (Vigna radiata (L.) Wilczek) is one of the legumes and pulses as protein-rich edible seeds, and referred to as grain legumes (Poehlman, 1991). Recently, the seeds of mungbean had antioxidant activity and contained other health-enhancing materials such as isoflavones and phenolic compounds (Anwar et al., 2007; Oh et al., 2003). Mungbean flour (MF) was prepared by grinding, sieving, and dry milling with a fine screen (200 mesh/ inch), and isolated by wet-milling and air-classification processes. Flour yields approximately $75 \%$ from original weight of mungbean seeds (Poehlman, 1991). MF had lower water absorption capacity (WAC) than other legume flours, such as chickpea and lentil, but higher than that of wheat flour (Sosulski et al., 1976). Based on these previous results, MF and its products could be applied to meat system as water and meat binder (Lee and Chin, 2009). However, no research was performed the effect of various mungbean flour levels on the water binding and gelling ability of low-salt pork model sausages.

Thus, this study was performed to evaluate the effects of various mungbean flour levels on the quality characteristics of pork model sausages and also select the optimum level of mungbean flour to enhance the water retention and gelling properties of low-salt pork model sausages with or without microbial transglutaminase.

\section{Materials and Methods}

\section{Materials}

Fresh pork shoulder meats were taken from the cross- bred pigs (Landrace $\times$ Yorkshire $\times$ Duroc, grade A, $110 \mathrm{~kg}$ live weight) that were slaughtered at a local retail meat market and stored in a refrigerator for $24 \mathrm{~h}$. Pork meats were trimmed of all visible fats and connective tissues, and stored in a $-30^{\circ} \mathrm{C}$ freezer until used. Microbial transglutaminase (MTGase) was provided by Ajinomoto Food Ingredients (TG-TI, USA), and mungbean flour was purchased from local market (Hamyang NongHyup, Korea).

\section{The manufacture of pork model sausages}

Pork model sausages were manufactured with various levels of mungbean flour (experiment 1) and low-salt $(<1 \%)$ pork model sausages were also manufactured with various levels of mungbean flour with or without MTGase (experiment 2), according to the procedure of Lee et al. (2008). The pork shoulder meats were mixed with different formulations (Table 1). And then, the comminuted meat batters were mixed for $1 \mathrm{~min}$ using hand-type food mixer (Bowl Rest ${ }^{\mathrm{TM}}$ Mixer, Hamilton Beach/Proctor-Silex, Inc., USA). Pork meat batters were stuffed into centrifuge tubes, and then centrifuged for $1 \mathrm{~min}$ to remove bubbles. These sausage batters were stored in a refrigerator for $2 \mathrm{~h}$ to incubate with MTGase (Sakamoto et al., 1994). After sausage batters were cooked in a water bath (VS-1901W, Vision Scientific Co. Ltd., Korea) until the internal temperature reached to $72^{\circ} \mathrm{C}$ (heating at $80^{\circ} \mathrm{C}$ ), they were quickly chilled in an ice and stored at a refrigerator until analyzed.

\section{Compositions analyses and sample pH}

The chemical compositions (moisture and fat contents) of samples were measured by dry oven (moisture content (\%), 950.46) and Soxhlet extraction (fat content (\%), 991.36) methods according to AOAC (2000). A $10 \mathrm{~g}$ of sausage samples were mixed with $90 \mathrm{~mL}$ deionized-water and then $\mathrm{pH}$ values of homogenized samples were measured using a pH meter (Model 340, Mettler-Toledo, Switzerland).

\section{Color measurements}

The core color of the sausage sample was measured using Color Reader (CR-10, Minolta Co. Ltd., Japan). Color values were expressed by Hunter L (lightness), a (redness), and b (yellowness) (White plate standard: $\mathrm{L}=$ $91.3 \pm 0.95, \mathrm{a}=1.43 \pm 0.35, \mathrm{~b}=-1.30 \pm 1.21)$.

\section{Cooking yield}

Cooking yields of sausage samples were measured by weighing before and after cooking at $80^{\circ} \mathrm{C}$ until the inter- 
Table 1. The formulation (\%) of pork model sausages as affected by various levels of mungbean flour and/or microbial transglutaminase treatment

\begin{tabular}{|c|c|c|c|c|c|c|c|}
\hline \multirow{2}{*}{\multicolumn{2}{|c|}{ Treatments ${ }^{1)}$}} & Meat & Added Water & "Salt & "STPP ${ }^{2)}$ & 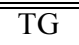 & $\mathrm{MF}^{3)}$ \\
\hline & & \multicolumn{6}{|c|}{$(\%)$} \\
\hline \multicolumn{8}{|c|}{ Experiment 1} \\
\hline \multirow{5}{*}{ MF levels (\%) } & 0.0 & 70.0 & 28.1 & 1.50 & 0.40 & - & - \\
\hline & 0.3 & 70.0 & 27.8 & 1.50 & 0.40 & - & 0.30 \\
\hline & 0.6 & 70.0 & 27.5 & 1.50 & 0.40 & - & 0.60 \\
\hline & 1.2 & 70.0 & 26.9 & 1.50 & 0.40 & - & 1.20 \\
\hline & 2.4 & 70.0 & 25.7 & 1.50 & 0.40 & - & 2.40 \\
\hline \multicolumn{8}{|c|}{ Experiment 2} \\
\hline \multirow{2}{*}{ MF $0.0 \%$} & NT & 70.0 & 28.7 & 0.90 & 0.40 & - & - \\
\hline & TG & 70.0 & 27.7 & 0.90 & 0.40 & 1.00 & - \\
\hline \multirow{2}{*}{ MF $0.3 \%$} & NT & 70.0 & 28.4 & 0.90 & 0.40 & - & 0.30 \\
\hline & TG & 70.0 & 27.4 & 0.90 & 0.40 & 1.00 & 0.30 \\
\hline \multirow{2}{*}{ MF $1.2 \%$} & NT & 70.0 & 27.5 & 0.90 & 0.40 & - & 1.20 \\
\hline & TG & 70.0 & 26.5 & 0.90 & 0.40 & 1.00 & 1.20 \\
\hline \multirow{2}{*}{ MF $2.4 \%$} & NT & 70.0 & 26.3 & 0.90 & 0.40 & - & 2.40 \\
\hline & TG & 70.0 & 25.3 & 0.90 & 0.40 & 1.00 & 2.40 \\
\hline
\end{tabular}

${ }^{11}$ Treatments: pork model sausages (PMS) manufactured with different levels of mungbean flour (MFL, 0.0-2.4\%) (experiment 1), and $1 \%$ microbial transglutaminase (TG) or not (NT) with different MFL (0.0-2.4\%) (experiment 2);

${ }^{2)}$ STPP: sodium tripolyphosphate;

${ }^{3)} \mathrm{MF}$ : mungbean flour.

nal temperature reached to $72^{\circ} \mathrm{C}$ and calculated as following formula:

Cooking yield $(\mathrm{CY}, \%)=$

(weight of samples after cooking / weight of samples before cooking) $\times 100$

\section{Expressible moisture}

To measure the expressible moisture (\%), an approximately $1.5 \mathrm{~g}$ of sausage samples was weighed and wrapped with filter papers (Whatman \#3), and then centrifuged at $1,000 \mathrm{~g}$ for $15 \mathrm{~min}$ using centrifuge (Model VS5500, Vision Science Co., Ltd, Korea) according to the modified method of Jauregui et al. (1981). Expressible moisture was calculated by expressed water from sample to filter paper as following formula:

Expressible moisture (EM, \%) =

(weight of expressed water in filter paper / weight of sample) $\times 100$

\section{Texture profile analysis}

Sausage samples were prepared with $13 \mathrm{~mm}$ of original height and $12.5 \mathrm{~mm}$ diameter using puncturing apparatus and performed texture profile analysis procedures using Instron Universal Testing Machine (Model 3344, USA). Textural properties of samples were expressed as hardness (gf), springiness (mm), and chewiness according to the method of Bourne (1978). Two cycles of compression test were performed with $75 \%$ of sample height with a $500 \mathrm{~N}$ load cell at a cross speed of $300 \mathrm{~mm} / \mathrm{min}$.

\section{Statistical analysis}

This study was performed in triplicates and data were analyzed by one-way analysis of variance (ANOVA) (experiment 1) and two-way ANOVA (experiment 2) using PASW Statistics 18 (SPSS 2010) program (2010) with a significance level of $5 \%$. In experiment 2 , interaction between factors (microbial transglutaminase treatment and various mungbean flour levels) and main effects of each factor were determined. If the interaction between factors were not significant $(p>0.05)$, data were pooled and posthoc analysis was performed using Duncan's multiple range test.

\section{Results and Discussion}

\section{Effects of various levels of mungbean flour on the quality characteristics of pork model sausages (Ex- periment 1)}

The quality characteristics of pork model sausages (PMS) manufactured with various levels of mungbean flour (MF) ranging from 0 to $2.4 \%$ are shown in Table 2 . MF level did not affect the $\mathrm{pH}$ values, chemical compositions (moisture and fat contents), and Hunter color values (lightness, L; redness, a; and yellowness, b) of PMS ( $p>$ 
Table 2. The quality characteristics of pork model sausages as affected by different additional levels of mungbean flour (Experiment 1)

\begin{tabular}{|c|c|c|c|c|c|c|}
\hline \multirow{2}{*}{ Parameters } & & \multicolumn{5}{|c|}{ "Mungbean flour level (\%) } \\
\hline & & 0 & 0.3 & 0.6 & 1.2 & 2.4 \\
\hline \multirow{2}{*}{$\mathrm{pH}$ values } & Mean & 6.26 & 6.26 & 6.27 & 6.28 & 6.29 \\
\hline & $\mathrm{SD}$ & 0.14 & 0.08 & 0.08 & 0.09 & 0.09 \\
\hline \multirow{2}{*}{ Moisture (\%) } & Mean & 79.8 & 79.5 & 79.2 & 79.1 & 77.6 \\
\hline & $\mathrm{SD}$ & 2.04 & 1.22 & 1.19 & 1.10 & 1.32 \\
\hline \multirow{2}{*}{ Fat $(\%)$} & Mean & 3.03 & 2.92 & 3.06 & 2.95 & 3.17 \\
\hline & $\mathrm{SD}$ & 0.92 & 0.78 & 0.68 & 0.62 & 0.96 \\
\hline \multirow{2}{*}{ Hunter L (lightness) } & Mean & 68.8 & 68.6 & 68.9 & 68.7 & 67.9 \\
\hline & $\mathrm{SD}$ & 2.97 & 3.78 & 3.53 & 3.88 & 3.20 \\
\hline \multirow{2}{*}{ Hunter a (redness) } & Mean & 8.45 & 8.52 & 8.58 & 8.10 & 8.32 \\
\hline & $\mathrm{SD}$ & 2.86 & 3.23 & 2.53 & 1.43 & 1.09 \\
\hline \multirow{2}{*}{ Hunter b (yellowness) } & Mean & 8.48 & 8.75 & 8.65 & 8.45 & 8.28 \\
\hline & $\mathrm{SD}$ & 0.39 & 0.30 & 0.40 & 0.15 & 0.37 \\
\hline \multirow{2}{*}{ Expressible moisture (\%) } & Mean & 20.3 & 19.0 & 17.9 & 16.8 & 16.2 \\
\hline & $\mathrm{SD}$ & 2.54 & 3.89 & 3.04 & 1.82 & 2.57 \\
\hline \multirow{2}{*}{ Cooking yield (\%) } & Mean & 98.5 & 99.0 & 99.0 & 99.1 & 99.3 \\
\hline & SD & 0.66 & 0.00 & 0.00 & 0.15 & 0.15 \\
\hline
\end{tabular}

Treatments: pork model sausages (PMS) manufactured with different levels of mungbean flour (0.0-2.4\%)

0.05). These results were similar to those of previous researches that different types (pea and chickpea) and levels $(2.5$ and $5 \%)$ of bean flour did not affect the $\mathrm{pH}$, lightness, and redness of low-fat bologna. However all treatments having $2.5-5 \%$ of bean flour was higher yellowness than the control (Sanjeewa et al., 2010).

The addition of MF did not affect the functional properties (expressible moisture, EM (\%) and cooking yield, CY (\%)) of PMS ( $p>0.05)$ (Table 2). Sanjeewa et al. (2010) reported that the chickpea flour increased cooking yield and reduced expressible moisture of low-fat Bologna. The pea flour also increased cooking yield at $5 \%$ and the effects of pea flour had similar expressible moisture and purge loss to those of chickpea flour on low-fat Bologna, regardless of levels (Sanjeewa et al., 2010). However, addition level (2.5-5\%) was higher than those of our research (0-2.4\%). Also, differences of cooking yield among treatments in this study were smaller than those of previous study (Sanjeewa et al., 2010) (Table 2). On the other hand, Pietrasik and Janz (2010) reported that 4\% of pea flour increased cooking yield of low-fat sausages, but did not influence expressible moisture of low-fat sausages. In addition, purge loss of low-fat sausages was affected by different types of flour (pea fiber, pea flour, pea starch, and wheat flour) $(p<0.05)$.

The addition of MF increased chewiness of PMS ( $p<$ $0.05)$ (Fig. 1) and hardness if the mungbean flour at the level of more than $1.2 \%$ was incorporated. Sanjeewa et al. (2010) noted that the addition of pea or chickpea flour significantly affected the textural properties of low-fat bologna, resulting in increased hardness, cohesiveness, springiness, and chewiness at the level higher than $2.5 \%$ $(p<0.05)$. These results showed that the addition of bean flours was effective to enhance the textural properties of comminuted meat products. Although the addition of MF into the low-fat sausages improved the textural hardness and chewiness, it contributed to improve the textural properties of comminuted meat products. However, further study will be required to figure out which components affect the textural properties in comminuted meat systems, based on protein-protein, protein-carbohydrate, and/or combined interactions.

\section{Effects of various levels of mungbean flour and/or microbial transglutaminase on the quality charac- teristics of low-salt pork model sausages (Experi- ment 2)}

Since the interaction between the microbial transglutaminase (MTGase) treatment and MF level was not significant $(p>0.05)$, data were pooled by different factors (MTGase treatment and MF level). The results of $\mathrm{pH}$ values, chemical compositions (moisture and fat contents), and Hunter color values are shown in Table 3. MTGase treatment decreased $\mathrm{pH}$ values of low-salt pork model sausages (LSPMS) $(p<0.05)$, but did not affect chemical compositions and Hunter color values of LSPMS ( $p>$ 0.05). However, MF level did not influence $\mathrm{pH}$ values, chemical compositions, and Hunter color values $(p>0.05)$. 

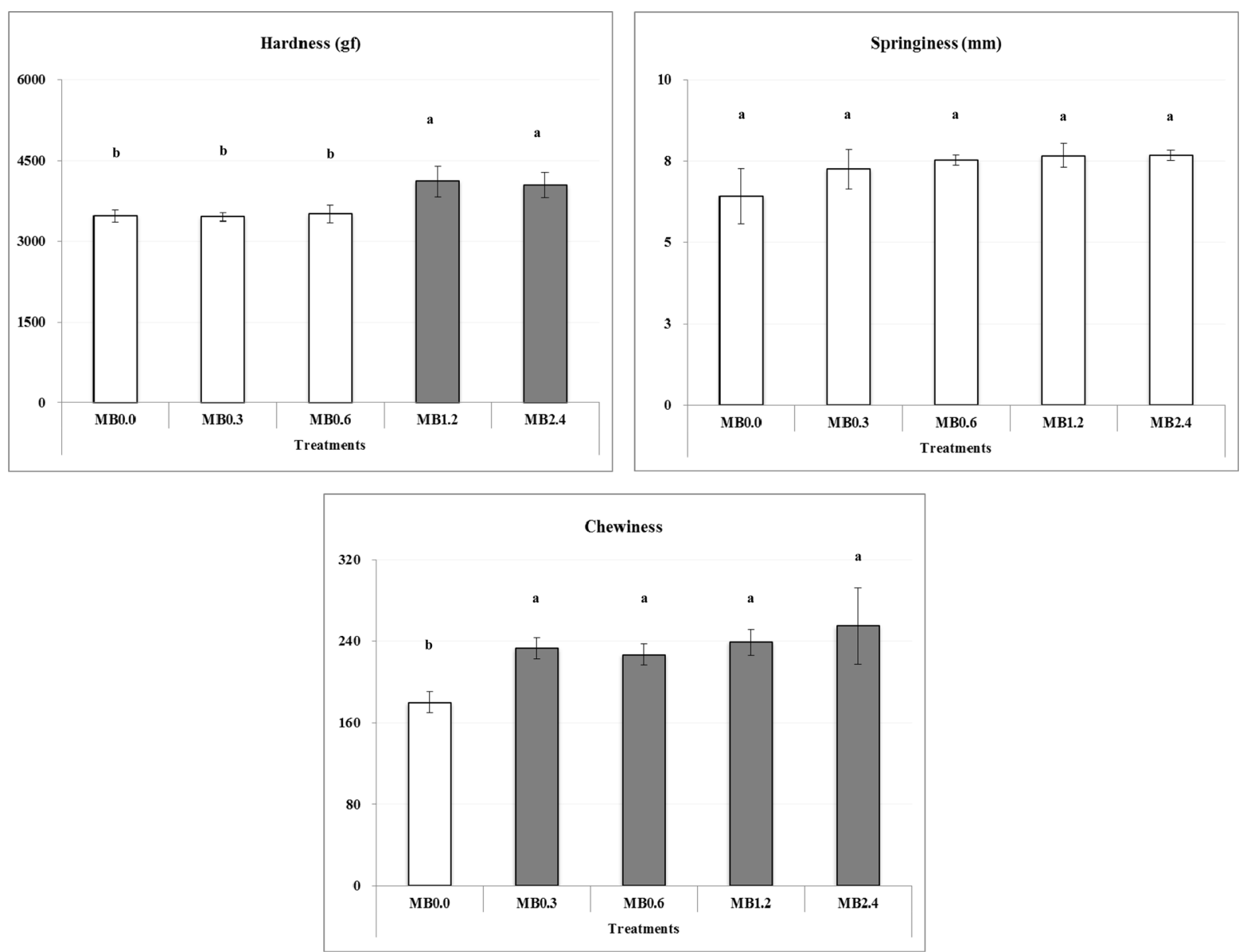

Fig. 1. The textural properties of pork model sausages as affected by various levels of mungbean flour (Experiment 1). Treatments: pork model sausages (PMS) manufactured with different levels of mungbean flour $(0.0-2.4 \%) .{ }^{\mathrm{a}-\mathrm{b}}$ Means with the same row having same superscripts are not different $(p>0.05)$.

Table 3. Pooled means of $\mathrm{pH}$ values, chemical compositions, and Hunter color values of low-salt pork model sausages as affected by different additional levels of mungbean flour and/or microbial transglutaminase treatment (Experiment 2)

\begin{tabular}{cccccccc}
\hline \hline Factors & pH values & Moisture (\%) & Fat (\%) & Hunter L (lightness) & Hunter a (redness) & Hunter b (yellowness) \\
\hline NT & $6.32^{\mathrm{a}}$ & 79.4 & 2.95 & 69.5 & 10.0 & 9.10 \\
TG & $6.22^{\mathrm{b}}$ & 78.0 & 3.48 & 69.4 & 9.20 & 9.30 \\
\hline MF 0.0 & 6.27 & 78.9 & 3.31 & 69.7 & 9.65 & 9.16 \\
MF 0.3 & 6.27 & 79.3 & 3.11 & 69.8 & 9.91 & 9.06 \\
MF 1.2 & 6.28 & 78.9 & 3.05 & 69.4 & 9.81 & 9.10 \\
MF 2.4 & 6.29 & 78.1 & 3.18 & 69.0 & 9.41 & 9.39 \\
\hline SEM & 0.02 & 1.10 & 0.61 & 0.95 & 0.79 & 0.22 \\
\hline
\end{tabular}

Factors: low-salt $(<1 \%)$ pork model sausages (LSPMS) as affected by microbial transglutaminase (MTGase) treatment (TG) or not (NT) and different additional levels of mungbean flour $(0.0,0.3,1.2$, and $2.4 \%)$.

${ }^{\mathrm{a}, \mathrm{b}}$ Means with the same column having no superscripts are not different in same factor (MTGase treatment or mungbean flour level) $(p>0.05)$.

*SEM: standard error means.

The results of water retention of LSPMS are shown in Fig. 2. The addition of MTGase did not affect the expressible moisture (\%), while increased level of MF reduced expressible moisture $(p<0.05)$. However, MTGase treatment reduced cooking yield of LSPMS $(p<0.05)$. Thus, the addition of MTGase affected the cooking yields and increased level of MF decreased the expressible moisture. These results showed that MTGase reduced water retention ability during heating process $(p<0.05)$ due to the production of cross-linkage produced (Kuraishi et al., 1997). In previous research results, excessive protein cross-linking and aggregation which may cause 


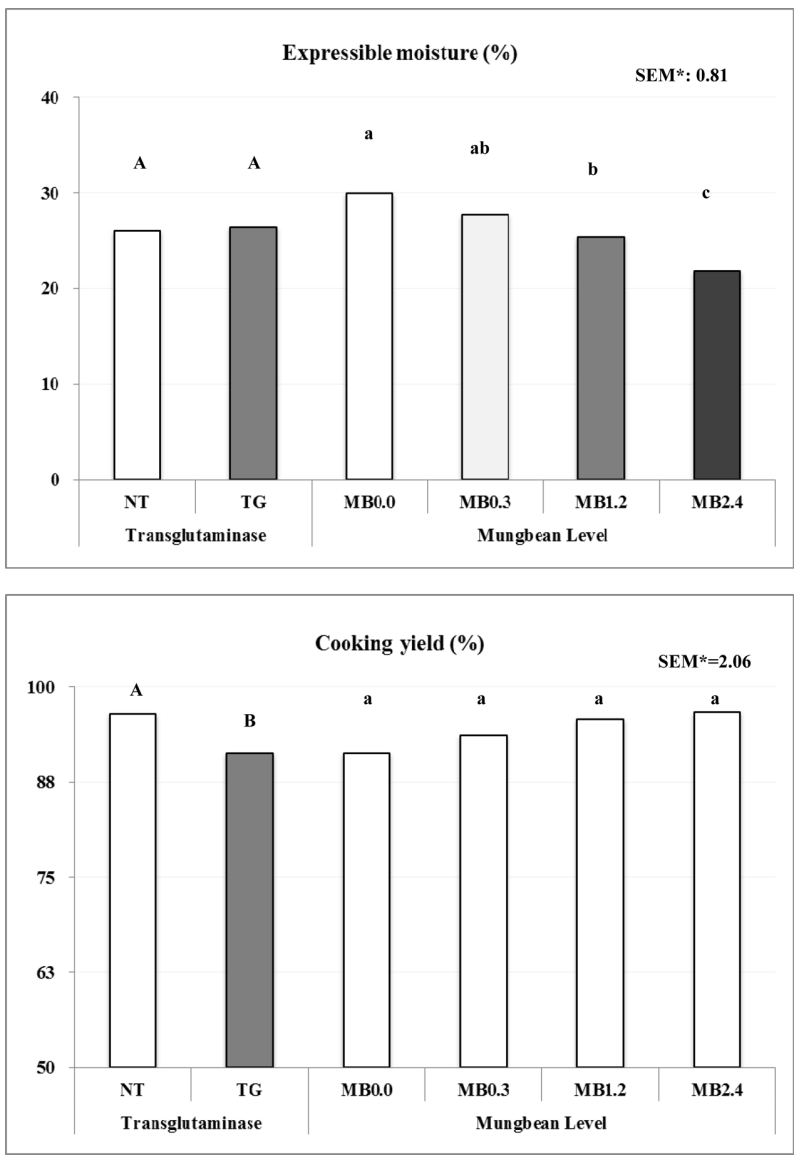

Fig. 2. Pooled means of expressible moisture and cooking yield of low-salt pork model sausages as affected by various levels of mungbean flour and/or microbial transglutaminase treatment (Experiment 2). ${ }^{\mathrm{A}-\mathrm{B}, \mathrm{a}-\mathrm{c}}$ Means with the same superscripts are not different in same factor (microbial transglutaminase treatment or mungbean flour level) $(p>0.05)$. *SEM: standard error mean.

moisture loss during cooking was observed (Chin et al., 2009a, b). When sodium caseinate was used as substrates for MTGase in the manufacture of reduced-salt restructured pork ham processing, it reduced cooking loss as compared to that of control which was not included binding agent or the combination of whey protein isolate and MTGase (Lee and Chin, 2011). Therefore, these results indicated that modifications of ingredients with optimum levels and combination with other ingredients or processing techniques might be beneficial to keep the water retention of LSPMS.

The addition of MTGase increased most textural characteristics, such as hardness, springiness, and chewiness (Fig. 3). On the other hand, increased level of MF improved the springiness of LSPMS $(p<0.05)$, but did not influence the other textural properties $(p>0.05)$ (Fig. 3). These results indicated that the addition of MTGase or MF could compensate the textural defects of LSPMS.
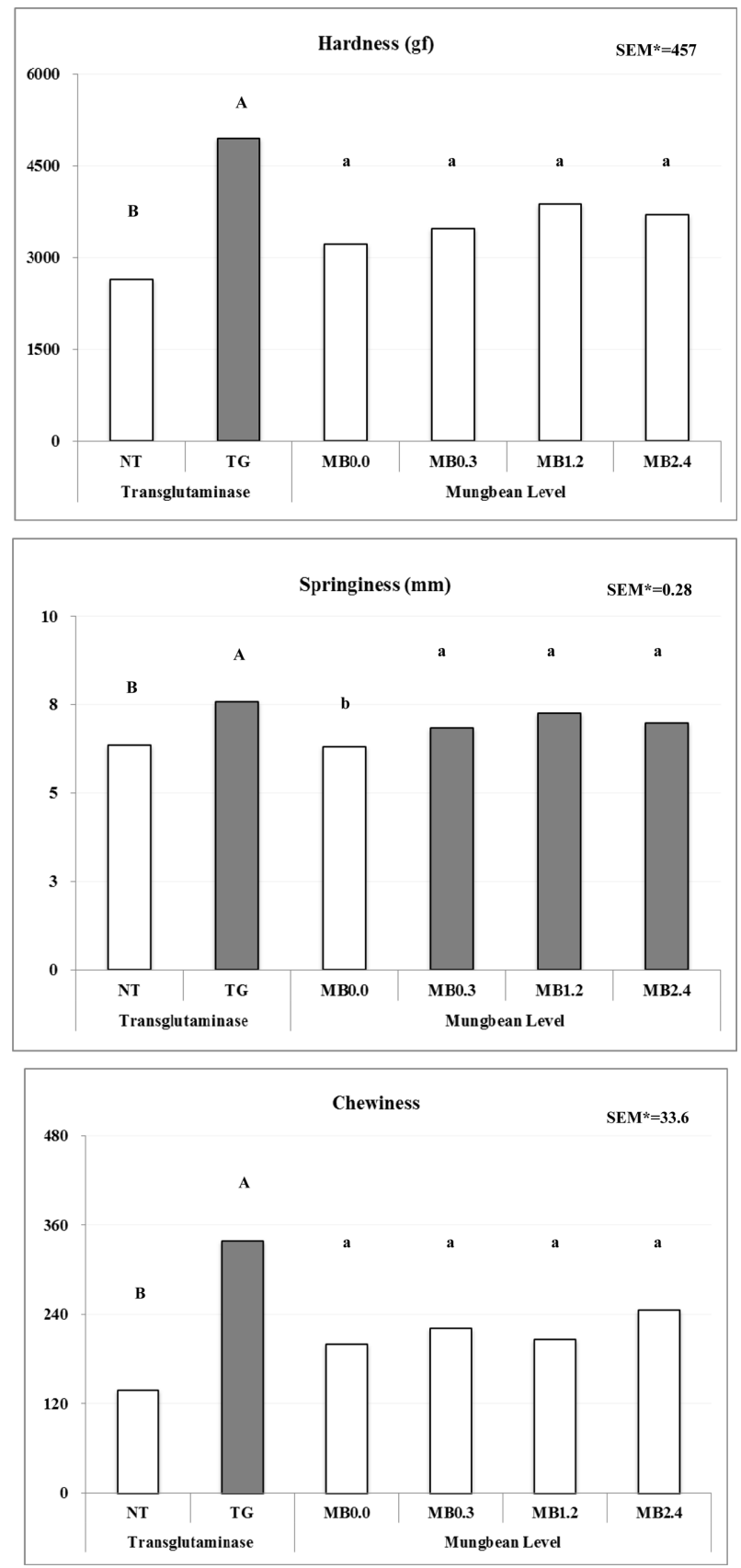

Fig. 3. Pooled means of textural properties of low-salt pork model sausages as affected by various levels of mungbean flour and/or microbial transglutaminase treatment (Experiment 2). ${ }^{\mathrm{A}-\mathrm{B}, \mathrm{a}-\mathrm{b}}$ Means with the same superscripts are not different in same factor (microbial transglutaminase treatment or mungbean flour level) $(p>0.05)$. ${ }^{*}$ SEM: standard error mean.

Therefore, at least $1.2 \%$ of MF level could be recommended to improve both the water retention and textural properties of LSPMS. Based on these results, mungbean protein may interaction with MTGase on the low-salt comminuted meat systems. Therefore, further study might be needed to identify the mechanisms of interaction between 
MTGase and functional components induced from MF.

\section{Acknowledgements}

This study was financially supported Chonnam National University in the program 2009 and partially supported by the Brain Korea 21 program (Center for the control of animal hazards using biotechnology), Chonnam National University, Gwangju, Korea.

\section{References}

1. AHA (2000) American heart association guidelines: Revision 2000. Circulation 102, 2284-2299.

2. AHA (2006) Soy protein, isoflavones, and cardiovascular health. Circulation 113, 1034-1044.

3. Anwar, E., Latif, S., Przyblski, R., Sultana, B., and Ashraf, M. (2007) Chemical composition and antioxidant activity of seeds of different cultivars of mungbean. J. Food Sci. 72, 503-510.

4. AOAC (2000) Official methods of analysis of AOAC Intl. 17th edition. Method. 950.46, 991.36. Association of Analytical Chemists. Gaithersberg, MD, USA.

5. Arihara, K. (2005) Strategies for designing novel functional meat products. Meat Sci. 74, 219-229.

6. Bourne, M. C. (1978) Texture profile analysis. Food Technol. 32, 62-66.

7. Chin, K. B. and Lee, H. C. (2002) Development of low-fat meat processing technology using interaction between meat proteins and hydrocolloids - II. Development of low-fat sausages using the results of model study. J. Korean Soc Food Sci Nutr. 31, 629-635.

8. Chin, K. B., Go, M. Y., and Xiong, Y. L. (2009a) Effect of soy protein substitution for sodium caseinate on the transglutaminase-indeced cold and thermal gelatin of myofibrillar protein. Food Res. Int. 42(10), 941-948.

9. Chin, K. B., Go, M. Y., and Xiong, Y. L. (2009b) Konjac flour improved textural and water retention properties of transglutaminase-mediated, heat-induced porcine myofibrillar protein gel: Effect of salt level and transglutaminase incubation. Meat Sci. 81, 565-572.

10. Dube, M., Schafer, C., Neidhart, S., and Carle, R. (2007) Texturisation and modification of vegetable proteins for food applications using microbial transglutaminase. Eur. Food Res. Technol. 225, 287-299.

11. Duranti, M. and Gius, C. (1997) Legume seeds: Protein content and nutritional value. Field Crops Res. 53, 31-45.

12. Fernandez-Gines, J. M., Fernandez-Lopez, J., Sayas-Barbera, E., and Perez-Alvarez, J. A. (2005) Meat products as functional foods: A review. J. Food Sci. 70, 37-43.

13. Jauregui, C. A., Regenstein, J. N., and Baker, R. C. (1981) A simple centrifugal method for measuring expressible moisture, a water binding property of muscle foods. J. Food Sci. 46, 1271, 1273.
14. Jimenez-Colmenero, F., Carballo, J., and Cofrades, S. (2001) Healthier meat and meat products: Their role as functional foods. Meat Sci. 59, 5-13.

15. Kashiwagi, T., Yokoyama, K., Ishikawa, K., Ono, K., Ejima, D., Matsui, H., and Suzuki, E. (2002) Crystal structure of microbial transglutaminase from Streptoverticillium mobaraense. J. Biol. Chem. 277, 44252-44260.

16. Ko, K. P., Park, S. K., Park, B., Yang, J. J., Cho, L. Y., Kang, C., Kim, C. S., Gwack, J., Shin, A., Kim, Y., Kim, J., Yang, H. K., Kang, D., Chang, S. H., Shin, H. R., and Yoo, K. Y. (2010) Isoflavones from phytoestrogens and gastric cancer risk: A nested case-control study within the Korean multicenter cancer cohort. Cancer Epidemiol. Biomarkers Prev. 19, 1292-1300.

17. Kuraishi, C., Sakamoto, J., Yamazaki, K., Susa, Y., Kuhara, C., and Soeda, T. (1997) Production of restructured meat using microbial transglutaminase without salt or cooking. J. Food Sci. 62, 488-490, 515.

18. Kuraishi, C., Yamazaki, K., and Susa, Y. (2001) Transglutaminase: Its utilization in the food industry. Food Rev. Int. 17, 221-246.

19. Larkin, T., Price, W. E., and Astheimer, L. (2008) The key importance of soy isoflavone bioavailability to understanding health benefits. Crit. Rev. Food Sci. Nutr. 48, 538-552.

20. Lee, H. C. and Chin, K. B. (2009) Physicochemical, textural, and sensory properties of low-fat/reduced-salt sausages as affected by salt levels and different type and level of milk proteins. Food Sci. Biotechnol. 18, 36-42.

21. Lee, H. C. and Chin, K. B. (2011) Evaluation of various salt levels and different dairy proteins in combination with microbial transglutaminase on the quality characteristics of restructured pork ham. International J. Food Sci. Technol. 46(7), 1522-1528.

22. Lee, H. C., Park, S. Y., and Chin, K. B. (2008) Evaluation of functional and textural properties of low-salt comminuted meats as affected by different hydrocolloids and transglutaminase. Proceed. $54^{\text {th }}$ Int. Congress Meat Sci. Technol. Cape Town, South Africa, p. 97.

23. Martins, V. B. and Netto, F. M. (2006) Physicochemical and functional properties of soy protein isolate as a function of water activity and storage. Food Res. Int. 39, 145-153.

24. Min, B. and Green, B. W. (2008) Use of microbial transglutaminase and nonmeat proteins to improve functional properties of low $\mathrm{NaCl}$, phosphate-free patties made from channel catfish (Ictalurus punctatus) belly flap meat. J. Food Sci. $\mathbf{7 3}$ (5), 218-226.

25. Motoki, M. and Seguro, K. (1998) Transglutaminase and its use for food processing. Trends Food Sci. Technol. 9, 204210.

26. Oh, H. S., Kim, J. H., and Lee, M.H. (2003) Isoflavone contents, antioxidative and fibrinolytic activities of red bean and mungbean. Korean J. Soc. Food Cookery Sci. 19, 263-270.

27. Pietrasik, Z. and Janz, J. A. M. (2010) Utilization of pea flour, starch-rich and fiber-rich fractions in low fat bologna. Food Res. Int. 43, 602-608.

28. Poehlman, J. M. (1991) The mungbean. Colorado, USA: West- 
view Press.

29. Rakosky, J. (1970) Soy products for the meat industry. J. Agri. Food Chem. 18, 1005-1009.

30. SACN (2003) Salt and health. Scientific advisory committee on nutrition. The Stationery Office, Norwich, UK.

31. Sakamoto, H., Kumazawa, Y., and Motoki, M. (1994) Strength of protein gels prepared with microbial transglutaminase as related to reaction conditions. J. Food Sci. 59, 866-871.

32. Sanjeewa, W. G. T., Wanasundara, J. P. D., Pietrasik, Z., and Shand, P. J. (2010) Characterization of chickpea (Cicer arietinum L.) flours and application in low-fat pork bologna as a model system. Food Res. Int. 43, 617-626.

33. Sosulski, F., Garratt, M. D., and Slinkard, A. E. (1976) Functional properties of ten legume flours. J. Can. Inst. Food Sci. Technol. 9, 66-69.

34. SPSS (2010) PASW Statistics 18 for windows. Chicago IL, USA.

35. Trout, G. R. and Schmidt, G. R. (1984) Effects of reduced salt $(\mathrm{NaCl})$ levels on sensory and instrumental evaluation of frankfurters. J. Food Sci. 49, 687-694.

$\overline{\text { (Received 2012.11.14/Revised 2013.3.18/Accepted 2013.3.26) }}$ 